\title{
Hormone Resistance in Breast Cancer
}

\author{
Alaa Kandil \\ Professor of Clinical Oncology, Alexandria School of Medicine
}

Corresponding Author: Alaa Kandil

Hormonal therapy is one of the oldest known breast cancer treatments, being also known as an early form of targeted therapy. Hormone receptors (estrogen (ER) $\&$ progesterone(PR)) are usually expressed in $60-70 \%$ of breast cancer patients ${ }^{1}$.

Unfortunately, with the use of all available hormonal therapy agents, resistance to such treatment occurs in a substantial percentage of patients and that applies to early stage and metastatic disease.

Recent evidence suggests that common molecular adaptations occur during resistance to hormonal therapy agents that use various signal transduction pathways, often involving cross-talk with a retained and functional estrogen receptor (ER) protein. This cross-talk appears to take place at different levels ${ }^{2}$.

Extensive research has been focusing on the problem of hormone resistance trying to understand the underlying molecular mechanisms and identifying cellular pathways that are responsible for hormone resistance.

THE PROTO-ONCOGENE HER-2/neu (erbB-2) encodes a $185-\mathrm{kd}$ transmembrane glycoprotein and is a member of the epidermal growth factor receptor family ${ }^{3}$.

Preclinical studies have suggested that estrogendependent cultured human breast cancer cell lines are rendered hormone independent after transfection with multiple copies of the stably expressed HER-2/neu gene ${ }^{4-6}$.

Retrospective metastatic and adjuvant clinical studies in estrogen receptor (ER)-positive breast cancers have addressed this issue. Some have suggested that HER-2/neu overexpression is associated with hormone resistance ${ }^{7-9}$, whereas others have found no such association ${ }^{10-12}$.

On the same line, looking into more cellular pathways, in a subset of 114 hormone-responsive-breast-cancer-

\author{
E-mail: alaakandil@hotmail.com
}

patients treated with neoadjuvant letrozole alone or combined with metronomic cyclophosphamide, Generali et $a l .{ }^{13}$ reported that ER $\alpha$ form was an independent factor for sensitivity to chemoendocrine treatment, whereas HIF-1 $\alpha$ (hypoxia-inducible factor $1 \alpha$ ) and p44/42 MAPK (mitogen-activated protein kinase ) were independent factors for resistance. These findings have clear potential implications for future strategies in the management of clinical trials with aromatase inhibitors in the managemant of breast cancer ${ }^{13}$.

Recently, Phosphatidyl inositol 3-kinase (PI3K) pathway was identified as an important pathway in breast cancer, also found to be frequently altered with both amplifications and mutations in its encoding genes. PI3K pathway plays a major role in different cellular functions related to cell growth, proliferation and antiapoptosis. AKT is a serine/threonine kinase that has been demonstrated to play an important role in survival when cells are exposed to different apoptotic stimuli. Recent studies show that aberrant activation of AKT in breast carcinoma is associated with a poor prognosis and resistance to endocrine therapy and chemotherapy ${ }^{14,15}$.

mTOR (mammalian target of rapamycin) is the effector of the PI3K/AKT pathway, activation of mTOR results in phosphorylation of its own effectors (Fig. 1), the best studied of which are eukaryotic initiation factor 4E-binding protein1(4E-BP1) and S6 kinase1(S6K1) which is a key regulator of cell growth. S6K1 phosphorylates important cellular targets, including insulin receptor substrate 1 (IRS-1), eukaryotic initiation factor 4B, programmed cell death 4, eukaryotic elongation factor-2 kinase, mTOR, glycogen synthase kinase 3, and S6K1 Aly/REF-like target ${ }^{16}$.

The story started with the discovery of rapamycin that took place in 1975 on the island of Rapa Nui, from which it derives its name. Initially developed as an antibiotic, it was noted that rapamycin possesses antiproliferative properties, especially 
against lymphocytes. Thus, the agent was studied as an immunosuppressive and eventually approved for prophylaxis of renal allograft rejection. In 1991, the target of rapamycin was discovered in yeast and named target of rapamycin (TOR) ${ }^{17}$. The only known homolog in mammals was subsequently cloned and called mammalian target of rapamycin, or mTOR ${ }^{18}$.

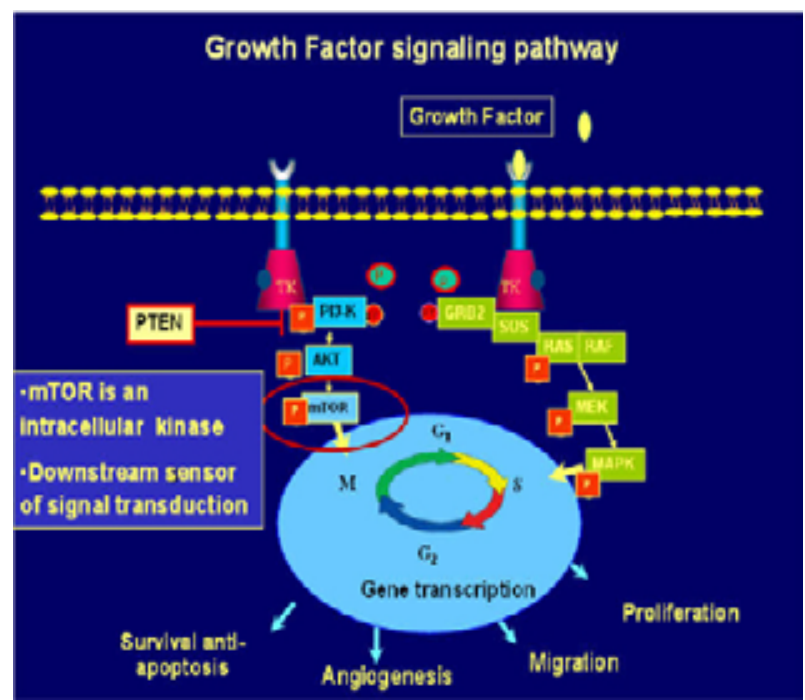

Figure 1: PI3K/AKT/mTOR pathway.

Most recently, we have three rapamycin analogs in cancer clinical trials: temsirolimus, everolimus, and deforolimus. They have efficacy in a wide range of malignancies including breast cancer, renal cell carcinoma (RCC), sarcoma, lymphoma, leukemia, glioblastoma, endometrial carcinoma, and neuroendocrine carcinomas.

In the GINECO phase II study ${ }^{19}$, postmenopausal breast cancer (hormone positive, Her-2-neu negative) patients with proven AI (Aromatase inhibitor) resistant/ progressive disease showed a 55\% reduction in the risk of death when they were treated with the combination of tamoxifen plus everolimus(TAMRAD) when compared to tamoxifen alone. Also patients who received everolimus had better clinical benefit rate, time to progression and overall survival (Fig. 2).

More exciting data were recently reported in a phase III trial (BOLERO2) by Baselga et al. ${ }^{20}$. In this trial, the combination of everolimus plus the steroidal aromatase inhibitor exemestane was used against exemestane alone in hormone responsive, Her-2 negative breast cancer patients $(\mathrm{N}=724)$ who progressed on non steroidal aromatase inhibitor therapy. The results showed a significantly better PFS in patients receiving the combination compared to exemestane alone (median 6.9 months vs 2.8 months, $P=0.001$ ), corresponding to a hazard ratio reduction of $57 \%$ (Fig. 3 ).

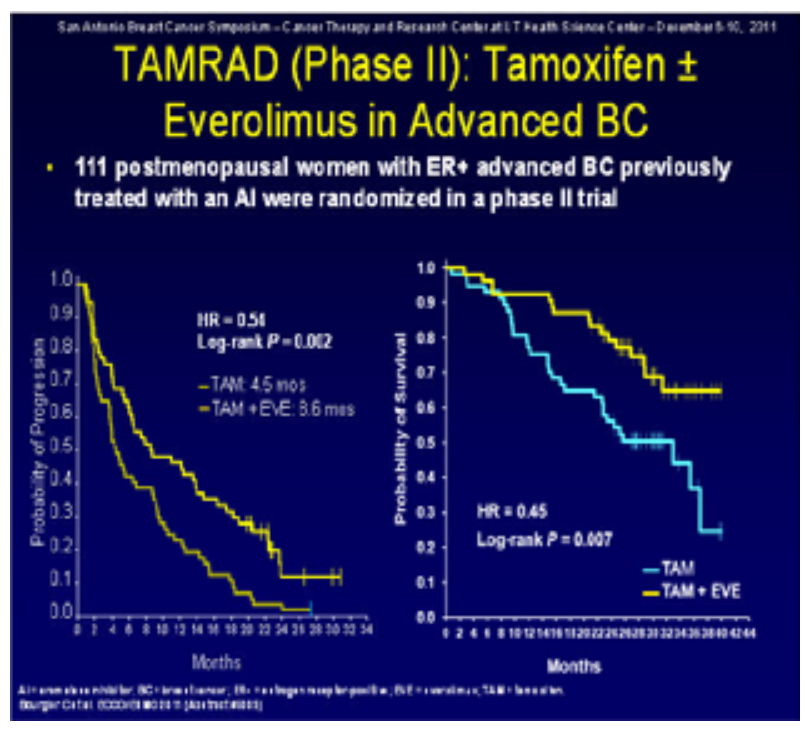

Figure2: GINECO results of PFS \& OS.

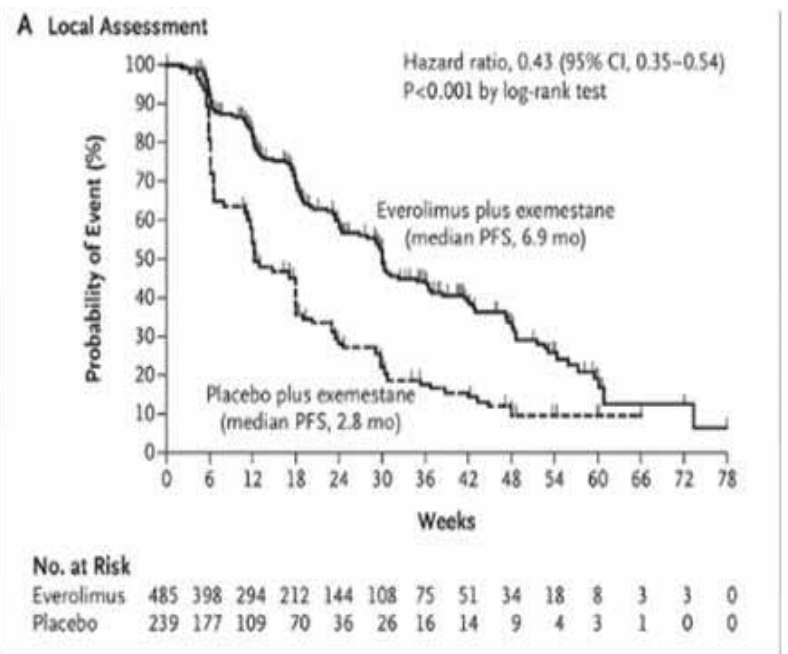

B Central Assessment

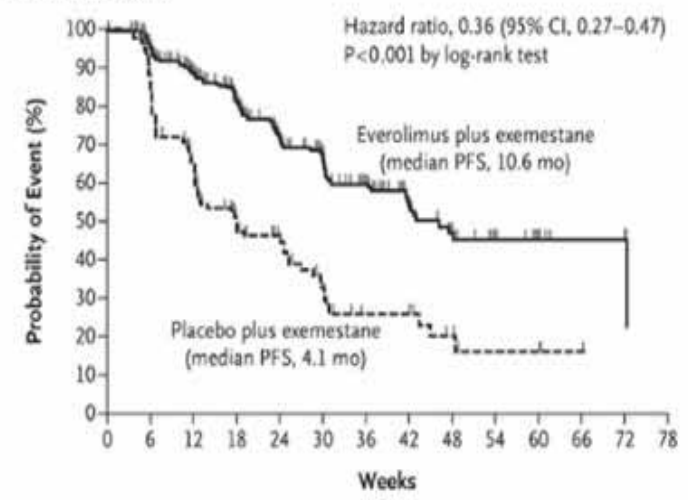

No. at Risk

$\begin{array}{llllllllllllllll}\text { Everolimus } & 485 & 385 & 281 & 201 & 132 & 102 & 67 & 43 & 28 & 18 & 9 & 3 & 2 & 0\end{array}$ Placebo $\quad \begin{array}{lllllllllllllll}239 & 168 & 94 & 55 & 33 & 20 & 11 & 11 & 6 & 3 & 3 & 1 & 0 & 0\end{array}$

Figure 3: Kaplan-Meier Plot of Progression-free Survival (BOLER2). 
The magnitude of benefit seen with this combination, considering the limited treatment options left for this subgroup of patients, is quite acceptable. Still, the benefits reported should be weighed against the increased side effects (mainly stomatitis, fatigue and diarrhea) observed with the combination.

Further research is needed to identify the subset of patients who would benefit the most of this combination oral therapy. More importantly is to look into the type of hormone resistance, being primary or secondary. Another great deal of work is needed in the area of combination with other targeted therapies so as to make the most of the mTOR inhibitors in a larger subsets of breast cancer patients.

\section{REFERENCES}

1. Osborne CK. Tamoxifen in the treatment of breast cancer. N.Engl.J.Med. 1998;339:1609-18.

2. Schiff R, Massarweh S, Shou J, Osborne CK. Breast cancer endocrine resistance: How growth factor signaling and estrogen receptor coregulators modulate response. Clin.Cancer Res. 2003;9(1 pt 2):447S-54S.

3. Coussens L, Yang-Feng TL, Liao YC, Chen E, Gray A, McGrath J, et al. Tyrosine kinase receptor with extensive homology to EGF receptor shares chromosomal location with neu oncogene. Science 1985;230(4730):1132-9.

4. Wright C, Nicholson S, Angus B, Sainsbury JR, Farndon $\mathrm{J}$, Cairns J, et al. Relationship between c-erbB-2 protein product expression and response to endocrine therapy in advanced breast cancer. Br.J.Cancer. 1992;65(1):118-21.

5. Benz CC, Scott GK, Sarup JC, Johnson RM, Tripathy D, Coronado E, et al. Estrogen-dependent, tamoxifen-resistant tumorigenic growth of MCF-7 cells transfected with HER2/ neu. Breast Cancer Res.Treat. 1992;24(2):85-95.

6. Pietras RJ, Arboleda J, Reese DM, Wongvipat N, Pegram MD, Ramos L, et al. HER-2 tyrosine kinase pathway targets estrogen receptor and promotes hormone-independent growth in human breast cancer cells. Oncogene 1995;10(12):2435-46.

7. Borg A, Baldetorp B, Fernö M, Killander D, Olsson H, Rydén $\mathrm{S}$, et al. ERBB2 amplification is associated with tamoxifen resistance in steroid-receptor positive breast cancer. Cancer Lett. 1994;81(2):137-44.

8. Leitzel K, Teramoto Y, Konrad K, Chinchilli VM, Volas G, Grossberg H, et al. Elevated serum c-erbB-2 antigen levels and decreased response to hormone therapy of breast cancer. J.Clin.Oncol. 1995;13(5):1129-35.

9. Berns EM, Foekens JA, van Staveren IL, van Putten WL, de Koning HY, Portengen H, et al. Oncogene amplification and prognosis in breast cancer: Relationship with systemic treatment. Gene 1995;159(1):11-8.
10. Soubeyran I, Quénel N, Mauriac L, Durand M, Bonichon F, Coindre JM. Variation of hormonal receptor, pS2, c-erbB-2 and GSTpi contents in breast carcinomas under tamoxifen: A study of 74 cases. Br.J.Cancer 1996;73(6):735-43.

11. Soubeyran I, Quénel N, Coindre JM, Bonichon F, Durand $\mathrm{M}$, Wafflart J, et al. pS2 protein: A marker improving prediction of response to neoadjuvant tamoxifen in post-menopausal breast cancer patients. Br.J.Cancer 1996;74(7):1120-5.

12. Elledge RM, Green S, Ciocca D, Pugh R, Allred DC, Clark GM, et al. HER-2 expression and response to tamoxifen in estrogen receptor-positive breast cancer: A Southwest Oncology Group Study. Clin.Cancer Res. 1998;4(1):7-12.

13. Generali D, Buffa FM, Berruti A, Brizzi MP, Campo L, Bonardi S, et al. Phosphorylated ERalpha, HIF-1alpha and MAPK signaling as predictors of primary endocrine treatment response and resistance in patients with breast cancer. J.Clin.Oncol. 2009;27(2):227-34.

14. Stemke-Hale K, Gonzalez-Angulo AM, Lluch A, Neve RM, Kuo WL, Davies M, et al. An integrative genomic and proteomic analysis of PIK3CA, PTEN and AKT mutations in breast cancer. Cancer Res. 2008;68(15):6084-91.

15. Cui X, Zhang P, Deng W, Oesterreich S, Lu Y, Mills GB, et al. Insulin-like growth factor-I inhibits progesterone receptor expression in breast cancer cells via the phosphatidylinositol 3-kinase/Akt/mammalian target of rapamycin pathway: Progesterone receptor as a potential indicator of growth factor activity in breast cancer. Mol. Endocrinol. 2003;17(4):575-88.

16. Meric-Bernstam F, Gonzalez-Angulo AM. Targeting the mTOR signaling network for cancer therapy. J.Clin.Oncol. 2009;27(13):2278-87.

17. Heitman J, Movva NR, Hall MN. Targets for cell cycle arrest by the immunosuppressant rapamycin in yeast. Science 1991;253(5022):905-99.

18. Brown EJ, Albers MW, Shin TB, Ichikawa K, Keith $\mathrm{CT}$, Lane WS, et al. A mammalian protein targeted by G1-arresting rapamycin-receptor complex. Nature 1994;369(6483):756-8.

19. Bachelot T, Bourgier C, Cropet C, Ray-Coquard I, Ferrero JM, Freyer G, et al. Randomized phase II trial of everolimus in combination with tamoxifen in patients with hormone receptor-positive, human epidermal growth factor receptor 2-negative metastatic breast cancer with prior exposure to aromatase inhibitors: AGINECO study. J.Clin.Oncol. 2012;30(22):2718-24.

20. Baselga J, Campone M, Piccart M, Burris III HA, Rugo HS, Sahmoud T, et al. Everolimus in postmenopausal hormone-receptor-positive advanced breast cancer. N.Engl.J.Med. 2012;366(6):520-9. 